Pacific Journal of Mathematics

NOTE ON THE KONHAUSER SETS OF BIORTHOGONAL
POLYNOMIALS SUGGESTED BY THE DAGUERRE

H. M. (HARL MOAN) SRIVASTAVN 


\title{
A NOTE ON THE KONHAUSER SETS OF BIORTHOGONAL POLYNOMIALS SUGGESTED BY THE LAGUERRE POLYNOMIALS
}

\author{
H. M. SRIVAstava
}

Two new classes of bilateral generating functions are given for the Konhauser polynomials $Y_{n}^{\alpha}(x ; k)$, which are biorthogonal to the Konhauser polynomials $Z_{n}^{\alpha}(x ; k)$ with respect to the weight function $x^{\alpha} e^{-x}$ over the interval $(0, \infty)$, $\alpha>-1$ and $k=1,2,3, \cdots$. The bilateral generating functions (1) and (2) below would reduce, when $k=1$, to similar results for the generalized Laguerre polynomials $L_{n}^{(\alpha)}(x)$. Furthermore, for $k=2$, these formulas yield the corresponding properties of the Preiser polynomials.

It is also shown how the bilateral generating function (2) can be applied to derive a new generating function for the product

$$
Y_{n}^{\alpha-k n}(x ; k) Z_{n}^{\beta}(y ; l),
$$

where $\alpha, \beta>-1, k, l=1,2,3, \cdots$, and $n=0,1,2, \cdots$.

1. Introduction. Recently, Joseph D. E. Konhauser discussed two polynomial sets $\left\{Y_{n}^{\alpha}(x ; k)\right\}$ and $\left\{Z_{n}^{\alpha}(x ; k)\right\}$, which are biorthogonal with respect to the weight function $x^{\alpha} e^{-x}$ over the interval $(0, \infty)$, where $\alpha>-1$ and $k$ is a positive integer. For the polynomials $Y_{n}^{\alpha}(x ; k)$, the following bilateral generating functions are derived in this paper:

$$
\begin{aligned}
\sum_{n=0}^{\infty} Y_{m+n}^{\alpha}(x ; k) \zeta_{n}(\boldsymbol{y} ; z) t^{n} & (1-t)^{-m-(\alpha+1) / k} \exp \left(x\left[1-(1-t)^{-1 / k}\right]\right) \\
= & \cdot F\left[x(1-t)^{-1 / k} ; \boldsymbol{y} ; z t^{q} /(1-t)^{q}\right]
\end{aligned}
$$

and

$$
\begin{aligned}
\sum_{n=0}^{\infty} Y_{m+n}^{\alpha-k n}(x ; k) \zeta_{n}(\boldsymbol{y} ; z) t^{n} \\
=(1+t)^{-1+(\alpha+1) / k} \exp \left(x\left[1-(1+t)^{1 / k}\right]\right) \\
\cdot G\left[x(1+t)^{1 / k} ; \boldsymbol{y} ; z t^{q} /(1+t)^{q}\right],
\end{aligned}
$$

where

$$
\begin{aligned}
& F[x ; \boldsymbol{y} ; t]=\sum_{n=0}^{\infty} \lambda_{n} Y_{m+q n}^{\alpha}(x ; k) \sigma_{n}(\boldsymbol{y}) t^{n}, \\
& G[x ; \boldsymbol{y} ; t]=\sum_{n=0}^{\infty} \lambda_{n} Y_{m+q n}^{\alpha-k q n}(x ; k) \sigma_{n}(\boldsymbol{y}) t^{n},
\end{aligned}
$$


$\lambda_{n} \neq 0$ are arbitrary constants, $m \geqq 0$ and $q \geqq 1$ are integers, $\sigma_{n}(\boldsymbol{y})$ is a nonvanishing function of $N$ variables $y_{1}, \cdots, y_{N}, N \geqq 1$, and

$$
\zeta_{n}(\boldsymbol{y} ; z)=\sum_{r=0}^{[n / q]}\left(\begin{array}{l}
m+n \\
n-q r
\end{array}\right) \lambda_{r} \sigma_{r}(\boldsymbol{y}) z^{r} .
$$

For $k=2$, our formulas (1) and (2) yield the corresponding properties of the polynomials introduced earlier by Preiser [5]. When $k=1$, both (1) and (2) would reduce to similar bilateral generating functions for the generalized Laguerre polynomials $L_{n}^{(\alpha)}(x)$, since (cf. [2] and [3])

$$
Y_{n}^{\alpha}(x ; 1) \equiv L_{n}^{(\alpha)}(x), \quad \alpha>-1 .
$$

Furthermore, in its special case when $m=0, q=1$ and $\sigma_{n}(\boldsymbol{y}) \equiv 1$, $n \geqq 0$, (1) would give us our earlier result [6, p. 485, Eq. (1)], while a similar special case of (2) is believed to be new.

2. Proofs of the bilateral generating functions (1) and (2). In our derivations of the bilateral generating functions (1) and (2), we shall require the following known results:

$$
\begin{aligned}
\sum_{n=0}^{\infty}\left(\begin{array}{c}
m+n \\
n
\end{array}\right) Y_{m+n}^{\alpha}(x ; k) t^{n}=(1-t)^{-m-(\alpha+1) / k} \\
\cdot \exp \left(x\left[1-(1-t)^{-1 / k}\right]\right) Y_{m}^{\alpha}\left(x(1-t)^{-1 / k} ; k\right)
\end{aligned}
$$

and

$$
\begin{aligned}
& \sum_{n=0}^{\infty}\left(\begin{array}{c}
m+n \\
n
\end{array}\right) Y_{m+n}^{\alpha-k n}(x ; k) t^{n}=(1+t)^{-1+(\alpha+1) / k} \\
& \cdot \exp \left(x\left[1-(1+t)^{1 / k}\right]\right) Y_{m}^{\alpha}\left(x(1+t)^{1 / k} ; k\right),
\end{aligned}
$$

where $m$ is an arbitrary nonnegative integer, and (by definition) $\alpha>-1$ and $k=1,2,3, \cdots$. The generating-function relationship (7) was proven independently by Calvez et Génin [1, p. A42, Eq. (6)] and Prabhakar [4, p. 803, Eq. (3.3)], while (8) is due to Calvez et Génin [1, p. A42, Eq. (7)].

If we substitute for the coefficients $\zeta_{n}(y ; z)$ from (5) into the left-hand side of (1), we find that

$$
\begin{aligned}
\sum_{n=0}^{\infty} Y_{m+n}^{\alpha}(x ; k) \zeta_{n}(\boldsymbol{y} ; z) t^{n} \\
\quad=\sum_{n=0}^{\infty} Y_{m+n}^{\alpha}(x ; k) t^{n} \sum_{r=0}^{[n / q]}\left(\begin{array}{c}
m+n \\
n-q r
\end{array}\right) \lambda_{r} \sigma_{r}(\boldsymbol{y}) z^{r} \\
\quad=\sum_{r=0}^{\infty} \lambda_{r} \sigma_{r}(\boldsymbol{y}) z^{r} t^{q r} \sum_{n=0}^{\infty}\left(\begin{array}{c}
M+n \\
n
\end{array}\right) Y_{M+n}^{\alpha}(x ; k) t^{n},
\end{aligned}
$$


where, for convenience, $M=m+q r, r=0,1,2, \cdots$.

The inner series can now be summed by applying the generating relation (7) with $m$ replaced by $M$, and the bilateral generating function (1) would follow if we interpret the resulting expression by means of (3).

Formula (2) can be proven similarly by appealing to (8) in place of (7), and we omit the details involved.

3. Applications. By assigning suitable values to the arbitrary coefficients $\lambda_{n}$, it is fairly straightforward to derive, from our formulas (1) and (2), a large variety of bilateral generating functions for the polynomials $Y_{n}^{\alpha}(x ; k)$ and $Y_{n}^{\alpha-k n}(x ; k)$, respectively. On the other hand, in every situation when the multivariable function $\sigma_{n}\left(y_{1}, \cdots, y_{N}\right)$ can be expressed as a suitable product of several simpler functions, we shall be led to interesting classes of multilateral generating functions for the Konhauser polynomials considered.

As a simple illustration, if in (2), (4) and (5) we set $m=0$, $q=1$,

(10) $\quad \lambda_{n}=\frac{(-1)^{n}}{\Gamma(\beta+\ln +1)}, \quad \sigma_{n}(\boldsymbol{y}) \equiv 1, n \geqq 0, \beta>-1, l=1,2,3, \cdots$,

and make use of the definition [3, p. 304, Eq. (5)], we shall readily arrive at the bilateral generating function

$$
\begin{gathered}
\sum_{n=0}^{\infty} \frac{n !}{\Gamma(\beta+\ln +1)} Y_{n}^{\alpha-k n}(x ; k) Z_{n}^{\beta}(y ; l) t^{n} \\
=(1+t)^{-1+(\alpha+1) / k} \exp \left(x\left[1-(1+t)^{1 / k}\right]\right) \\
H\left[x(1+t)^{1 / k},-y^{l} t /(1+t)\right],
\end{gathered}
$$

where, for convenience,

$$
H[x, t]=\sum_{n=0}^{\infty} Y_{n}^{\alpha-k n}(x ; k) \frac{t^{n}}{\Gamma(\beta+\ln +1)} .
$$

For $k=l=1$, the generating relation (11) would evidently reduce to a familiar result for the generalized Laguerre polynomials; indeed, (11) may also be looked upon as being complementary to our earlier result [6, p. 491, Eq. (14)].

\section{REFERENCES}

1. Léon-Claude Calvez et Robert Génin, Applications des relations entre les fonctions génératrices et les formules de type Rodrigues, C.R. Acad. Sci. Paris Sér. A-B, 270 (1970), A41-A 44 . 
2. Joseph D. E. Konhauser, Some properties of biorthogonal polynomials, J. Math. Anal. Appl., 11 (1965), 242-260.

3. - Biorthogonal polynomials suggested by the Laguerre polynomials, Pacific J. Math., 21 (1967), 303-314.

4. T.R. Prabhakar, On the other set of the biorthogonal polynomials suggested by the Laguerre polynomials, Pacific J. Math., 37 (1971), 801-804.

5. S. Preiser, An investigation of biorthogonal polynomials derivable from ordinary differential equations of the third order, J. Math. Anal. Appl., 4 (1962), 38-64.

6. H. M. Srivastava, On the Konhauser sets of biorthogonal polynomials suggested by the Laguerre polynomials, Pacific J. Math., 49 (1973), 489-492.

Received November 2, 1979. This work was supported, in part, by the Natural Sciences and Engineering Research Council of Canada under Grant A-7353.

UNIVERSITY OF VICTORIA

Victoria, British Columbia, Canada

V8W $2 \mathrm{Y} 2$ 


\section{PACIFIC JOURNAL OF MATHEMATICS}

\section{EDITORS}

DONALD BABBITT (Managing Editor)

University of Galifornia

Los Angeles, California 90024

HUGO RossI

University of Utah

Salt Lake City, UT 84112

C. C. MOORE AND ANDREW OGG

University of California

Berkeley, CA 94720
J. DUGUNDJI

Department of Mathematics University of Southern California Los Angeles, California 90007

R. FINN AND J. MILGRAM Stanford University

Stanford, California 94305

ASSOCIATE EDITORS

E. F. BECKENBACH

B. H. NeumanN

F. WOLF

K. YosHidA

\section{SUPPORTING INSTITUTIONS}

UNIVERSITY OF BRITISH COLUMBIA UNIVERSITY OF SOUTHERN CALIFONIA CALIFORNIA INSTITUTE OF TECHNOLOGY UNIVERSITY OF CALIFORNIA MONTANA STATE UNIVERSITY STANFORD UNIVERSITY UNIVERSITY OF HAWAII UNIVERSITY OF NEVADA, RENO UNIVERSITY OF TOKYO U'NIVERSITY OF UTAH NEW MEXICO STATE UNIVERSITY WASHINGTON STATE UNIVERSITY OREGON STATE UNIVERSITY UNIVERSITY OF OREGON UNIVERSITY OF WASHINGTON 


\section{Pacific Journal of Mathematics}

\section{Vol. 90, No. $1 \quad$ September, 1980}

Shashi Prabha Arya and M. K. Singal, On the locally countable sum

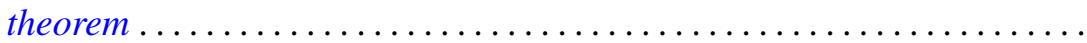

John Theodore Baldwin and David William Kueker, Ramsey quantifiers and

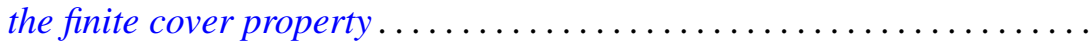

Richard Body and Roy Rene Douglas, Unique factorization of rational

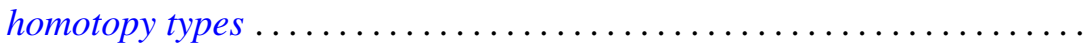

Ethan Bolker and Ben G. Roth, When is a bipartite graph a rigid

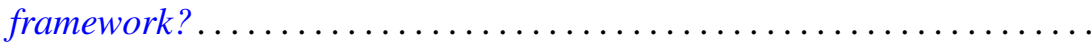

Alicia B. Winslow, Continua in the Stone-Čech remainder of $R^{2} \ldots \ldots \ldots$

Richard D. Carmichael and Elmer Kinji Hayashi, Analytic functions in tubes which are representable by Fourier-Laplace integrals ..............

Stephen D. Cohen, The Galois group of a polynomial with two indeterminate coefficients ..............................

Russell Allan Johnson, Strong liftings commuting with minimal distal

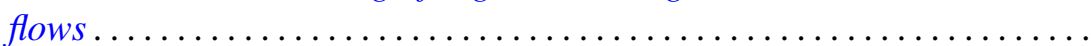

Elgin Harold Johnston, The boundary modulus of continuity of harmonic

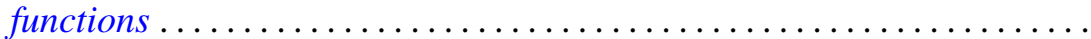

Akio Kawauchi and Takao Matumoto, An estimate of infinite cyclic

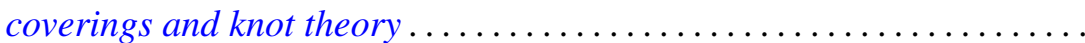

Keith Milo Kendig, Moiré phenomena in algebraic geometry: rational alternations in $\mathbf{R}^{2}$...

Roger T. Lewis and Lynne C. Wright, Comparison and oscillation criteria for selfadjoint vector-matrix differential equations .

Teck Cheong Lim, Asymptotic centers and nonexpansive mappings in conjugate Banach spaces .......................

David John Lutzer and Robert Allen McCoy, Category in function spaces.

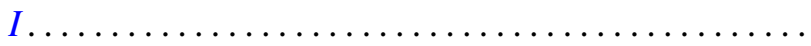

Richard A. Mollin, Induced p-elements in the Schur group ...

Jonathan Simon, Wirtinger approximations and the knot groups of $F^{n}$ in $S^{n+2}$

Robert L. Snider, The zero divisor conjecture for some solvable groups...

H. M. (Hari Mohan) Srivastava, A note on the Konhauser sets of biorthogonal polynomials suggested by the Laguerre polynomials...

Nicholas Th. Varopoulos, A probabilistic proof of the Garnett-Jones theorem on BMO.

Frank Arvey Wattenberg, $[0, \infty]$-valued, translation invariant measures on $N$ and the Dedekind completion of ${ }^{*} R \ldots \ldots \ldots \ldots . .$. 